\title{
Stock Spams: \\ Another Kind Of Stock Prices Manipulation
}

Taoufik Bouraoui, ESC Rennes School of Business, France

Mohamed Mehanaoui, SUP de CO Amiens, France

Bouchaib Bahli, ESC Rennes School of Business, France

\begin{abstract}
This research investigates the market reaction to an information-based manipulation called stock spams. The impact is focused on the liquidity variable which is measured by Amivest ratio. Using the event study methodology on a sample of penny stocks for the period February 2006 through October 2008, our findings suggest positive and significant abnormal liquidities for stocks targeted by manipulators during the event window. Robustness checks were performed using a non-parametric test. These results support the thesis that this kind of manipulation is a very flourishing business that manipulators exploit by simply purchasing stocks at low prices and selling them at higher prices.
\end{abstract}

Keywords: Business; Stock Spam; Event Studies; Liquidity

\section{INTRODUCTION}

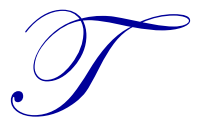

rading on the stock market requires great judgment and strategy about when to buy and when to sell. The rise and fall of prices is an ongoing process, but when they are manipulated, this can lead to big losses for investors. Usually, an inexplicable boost in the price and trading volume of a company's stock in the absence of good news is due to manipulative activities. Unfortunately, manipulation is something that investors deal with. It is part of the market dynamics and shows no signs of good performance. Manipulators exist in every market and are especially concentrated in emerging stock market where share prices are very low and highly unpredictable.

Market manipulation is a dishonest maneuver that attempts to interfere with the proper operation of the stock market and create artificially distorted stock prices. This leads to a reduction in market efficiency as trading decisions are not made on financial fundamentals.

Although it is illegal and may lead to prosecution and sanctions, manipulators do not fear the law and continue to influence stock prices. The risk of price manipulation is greater in OTC markets, such as the penny stock market, because stocks in these markets are bought and sold by one broker or a small group of brokers. Manipulators may buy a big quantity of OTC stocks at a low price which exerts undue influence on the price by engineering a false demand for the stock. This usually drives up the price. However, the stock's price does not reflect the real value of the issue and finishes by dropping when manipulators sell off their shares to unwitting investors.

American securities regulators estimate that manipulation of prices costs investors approximately $\$ 40$ billion per year ${ }^{1}$. These fraudulent schemes can ultimately have a devastating impact on the viability and working of these markets. Therefore, regulation of market manipulation is necessary to ensure investor confidence in the integrity of the securities markets and to promote an efficient market.

Manipulations of stock price can be achieved in multiple ways. Allen and Gale (1992) classify market manipulation practices into three types - action-based, trade-based, and information-based manipulation. The first

\footnotetext{
${ }^{1}$ owa Insurance Division, http://www.iid.state.ia.us/docs/investoreducation1.pdf, accessed May 9, 2008

(C) 2013 The Clute Institute http://www.cluteinstitute.com/
} 
category is based on actions that enable manipulators to influence stock prices. For example, at the time of equity issue, managers of corporations have the ability to alter stock prices in order to attract investors by giving them a false value of stocks. In the second category, manipulation is due to buying or selling securities by a person who misleads or deceives other participants about the value or the trading volume, without taking any actions. Aggarwal and Wu (2006) and Aktas and Doganay (2006) are interested in this type of manipulation, respectively, in the US and Turkish markets. The third category (information-based manipulation) occurs when a person disseminates false or misleading information to influence stock prices. Manipulators gain unfair advantage by spreading false information through stock promoters, news releases, Internet chat rooms, and bulletin boards to encourage other information-seeking investors to purchase securities. This type is the most used today to manipulate stock prices. Aggarwal and $\mathrm{Wu}$ (2006) mentioned the example of the young American, Jonathan Lebed, who bought several hundred shares of a Chinese company at a very low price (between $\$ 1.37$ and $\$ 2$ ). After a clever campaign taking the form of false information and comments published on the Bulletin Board stocks, he sold securities at $\$ 4.68$. Our paper focuses on this third type of manipulation and involves a new kind of information-based manipulation - stock spams.

Stock spams are electronic messages sent to influence microcap companies' stock through false and misleading information. After pumping the stock, manipulators make huge profits by selling their cheap stock into the market. Prior literature have studied the effect of stock spams on some variables like volume, return and volatility (Bohm and Holz, 2006; Frieder and Zittrain, 2007; Hanke and Hauser, 2008; Bouraoui, 2007, 2011). In this paper, we ask whether this form of manipulation affects the purchase and/or sale of securities while studying the impact on liquidity. To our knowledge, no study focused on the impact of this phenomenon on liquidity in the context of price manipulation, so we believe that our paper makes a modest contribution to this literature.

\section{LITERATURE REVIEW}

Stock market manipulation describes a deliberate attempt to influence the price of stocks by buying or selling in order to give the impression that the stocks are widely traded. It involves fraudulent changes in the natural rise and fall that comes along with market investments.

Allen and Gorton (1992) considered a trade-based manipulation model. In each equilibrium of their model, the uninformed manipulator makes zero profit, while the informed manipulator repeatedly purchases stocks, causing a large impact on prices, and sells with little effect to earn a profit. The authors conclude that manipulation is due to asymmetry between buy orders and sell orders. Kumar and Seppi (1992) focused on the manipulation in futures markets when contracts are settled in cash and find that manipulators are able to make profits by taking a position in a futures contract and subsequently trading in the spot market. However, these profits fall to zero when the number of manipulators increases. Felixon and Pelli (1999) examined the closing-price manipulation of 15 securities on the Finnish market. Using a simple regression model, they found that the results are not generally significant, indicating that manipulators do not always succeed to manipulate prices. Vitale (2000) examines manipulation in the foreign exchange market by informed traders who succeed to acquire an informational advantage in order to manipulate the market.

In information-based manipulation, Van Bommel (2003) investigated the case of rumors in financial markets and shows, that while using the model of Kyle (1985), agents who claim they have private or insider information are able to influence stock prices by disseminating rumors through magazines and word of mouth. These informed insiders are also studied by Chakraborty and Yilmaz (2004) who developed a model inspired from Glosten and Milgrom's (1985) model to show how informed insiders should trade to manipulate stock market. Their results show that by trading repeatedly, insiders can exert a power on the market and then make prices less sensitive to their trades. Pirrong (2004) used regression analysis and error correction models to determine whether change in prices in future markets is due to manipulation or if it simply refers to normal economic conditions. By analyzing the "cornering" of the soybean futures market in 1989 by Ferruzzi - a large Italian conglomerate - the author demonstrates that Ferruzzi had monopoly power, thus creating a distortion in prices of 5\% to $10 \%$. 
In the Taiwan stock exchange, Huang, Chen and Cheng (2005) examine the characteristics of manipulated stocks during the period 1991-2003. On the basis of 53 cases of manipulation, their results report a rise in trading volume, in return, and in volatility, which leads to a market inefficiency.

Aggarwal and $\mathrm{Wu}$ (2006) are also interested in the topic of manipulation. They identify 142 manipulation cases in the US market for the period 1999-2001. The authors observed that most manipulation cases occur in OTC markets, such as the Over-The-Counter Bulletin Board (OTCBB) and the Pink Sheets, which have much lower disclosure requirements for listed firms and less stringent securities regulations. During the manipulation period, they reported an increase in returns and volatilities of 51 stocks which have been the subject of price manipulation. Ögüt, Doganay and Aktas (2009) studied price manipulation in the Turkish financial market. Using 222 manipulation cases that occurred between 1995 and 2004, they developed sophisticated models to detect possible manipulation by observing some variables such as return, volume and volatility.

Manipulation can also be based on actions (action-based manipulation). However, this type of manipulation is less approached than other types because it requires taking a specific action other than trading to mislead the market. In this context, Vila (1989) involves a situation in which the manipulator, whose trades are concealed among those of liquidity traders, can take actions, such as a takeover bid, to enhance the value of the target firm. Bagnoli and Lipman (1996) also developed a model in which the manipulator announces a takeover bid to alter the target firm's stock price. Their results show that after stock prices rise, thus generating profits, the manipulator unwinds his position.

As explained above, stock market manipulation can occur in different settings. However, today some manipulators use the Internet as a new impetus to manipulate stock market by sending millions of emails containing false information in order to mislead potential investors. This new form of manipulation is called stock spams.

\section{STOCK SPAMS}

When the Internet is combined with stock markets, it becomes a great adventure playground for swindlers. This way of communication has greatly facilitated this type of skid for people and gave birth to stock spams.

Stock spams - also called "pump and dump" - are messages sent with the goal of boosting the price of microcap companies through recommendations based on false or misleading statements.

This scheme is based on a simple principle - the manipulator starts by gradually buying a large quantity of stocks. Then he sends messages that promise that the stocks of some companies are going to explode or shoot up in price. This encourages potential investors to invest in these stocks; those who believe in such information buy securities in significant quantities, thus raising the share price. Finally, the dishonest speculator - the originator of all these activities - sells stocks at higher prices, thus making huge profits on their own investment. The victims of this practice often lose a considerable amount of their investment as the stock falls back down after the process is complete. Figure 1 describes the mechanism of stock spams.

During phase P1, the manipulator buys a large quantity of stocks at a low price. At date A, he launches his campaign by sending millions of messages. Gullible investors buy stocks on the basis of the false information contained in the messages (date B). P2 is the phase during which the stock prices climb following bulk purchases. At date $\mathrm{C}$, the manipulator sells all the stocks at high prices and he makes a huge gain. Finally, during phase P3, the share price drops to restore its original value. 


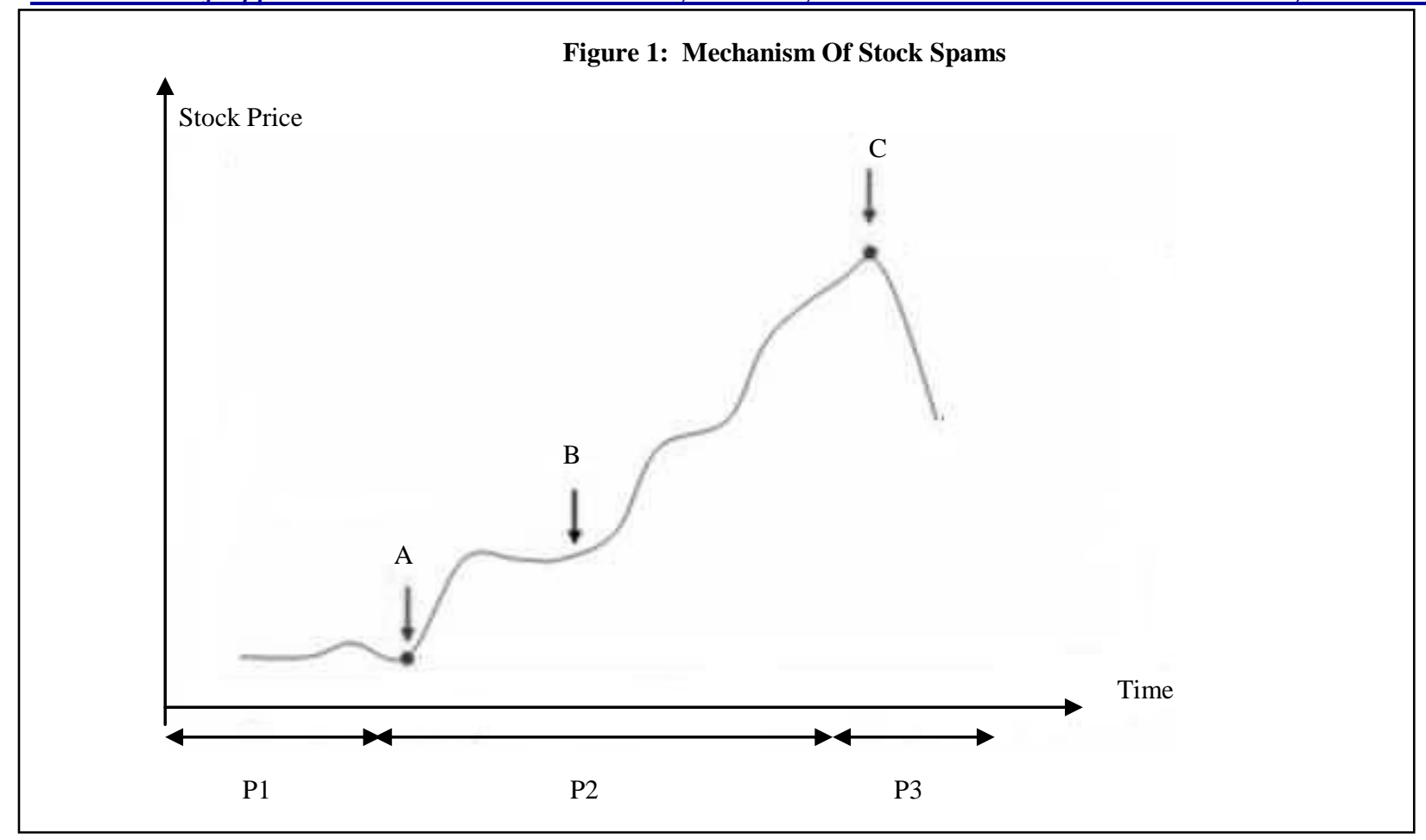

Stock spams are illegal; however, illegality does not prevent manipulators from pursuing their activities. In fact, manipulators use sophisticated methods to create new forms of spam to mask similarity between messages and to escape anti-spam filters. After using the spam text, the spam picture, the spam PDF, ..., they developed a recent technique called a spam video. The idea is ingenious; in the body of the message, a link is presented on which the investor is asked to click in order to watch a video that lasts less than one minute. By clicking on the link contained in the message, a high quality video of a real duration of 30 seconds, speaking about advertisement for stock market investments, is displayed. At the end of the video, the investor is redirected automatically to a web page which proposes a subscription in a newsletter to inform him on the opportunity of financial investments related to the video viewed at the beginning. So, in front of these sophisticated techniques, the fight against this form of manipulation is becoming increasingly difficult. The filters of detection of a given form of spam are hardly effective and manipulators develop new tactics to spread their messages.

Few researchers have attempted to assess the impact of this phenomenon on market activity. Bohme and Holz (2006) studied the impact of these messages on the financial market between November 2004 and February 2006. On the basis of 7,606 messages, 111 stocks have been targeted. They used a multiple regression model and found that the volume on a stock exchange security mentioned in a spam increased, on average, $215.2 \%$. This number falls to $154.1 \%$ when the message is transmitted before opening hours of the market. The authors note that prices climb $+1.7 \%$ the first day of the campaign. Frieder and Zittrain (2007) show the effectiveness of stock spams to alter prices. Through an analysis of 3,669 companies containing over 500 distinct stocks listed in the Pink Sheets between January 2004 and July 2005, they found that a spammer makes, in two days, a medium benefit of $4.9 \%$ of the share value, while the investor sees his investment, in two days, falling $8 \%$. They also noted an increase of volumes and positive returns of the stocks targeted by spams. Similarly, Hanke and Hauser (2008) examined the effect of stock spams on return, volatility and turnover. They constituted a sample of 235 firms that were the subject of spam during 2005. Besides the presence of significant and positive impact on all three variables during the first day of the event, the authors mention that repeated spamming on successive days generates an additional demand on behalf of investors for targeted securities. Finally, Bouraoui $(2007,2009)$ studied the reaction of volumes and returns of 110 firms listed on either the Over-The-Counter Bulletin Board (OTCBB) or the Pink Sheets after the sending of stock spams. The author finds positive and significant variations of volumes throughout the event window, while returns reacted positively the first day and negatively the following days. 


\section{EMPIRICAL APPROACH}

\section{Measuring Liquidity}

Liquidity of financial assets (stock, bond, mutual fund, etc.) is an important component of investment strategies. It refers to the ability of an asset to quickly be converted into cash and without seeing a change in price. The traditional measures of liquidity used in the literature are volume of trades, the bid-ask spread of a security and the depth of the market. As the first measure (volume of trades) was our focus in a previous paper (Bouraoui, 2007) and the bid-ask prices are not available for our sample, we choose the depth of market as a measure of liquidity. This measure expresses the ability of a market to sustain a large quantity of orders without impacting the share prices. To estimate depth, we use the liquidity ratio - also called the Amivest ratio. Several researchers (Amihud, Mendelson and Lauterbach, 1997; Berkman and Eleswarapu, 1998; Muscarella and Piwowar, 2001; Adaoglu, 2005; etc.) suggest that this indicator is a very good measure in capturing liquidity. Moreover, it's so easy to implement. For these reasons, we have opted for this measure.

The Amivest ratio represents the dollar value of trading associated with a $1 \%$ change in share price. In other words, a high Amivest ratio means investors can trade a large quantity of securities without significant change in prices. Hence, an increase in the value of this ratio results in a rise in liquidity. According to the formula of Amivest ratio, liquidity of stock $i$ can be computed as follows:

$$
\text { Amivest }_{i}=\frac{1}{J} \sum_{t=1}^{J} \frac{V o l_{i}}{\left|R_{i}\right|}
$$

where

$J$ : the number of days of the study period where return is different from 0

Vol $_{t}$ : trading volume in dollars of stock $i$

$R_{t}$ : return of stock $i$

However, this formula is an average calculated for every security and does not depend on time. Since we are interested in calculating the liquidity for every stock $i$ and at every date $t$, we should use the following Amivest formula:

$$
\text { Amivest }_{i, t}=\frac{\text { Vol }_{i, t}}{\left|R_{i, t}\right|}
$$

where

$V_{i, t}$ : trading volume in dollars of stock $i$ at date $t$

$R_{i, t}:$ return of stock $i$ at date $t$

\section{DATA}

We hand-collect data on stock price manipulation cases from the website http://www.spamnation.info/stocks/ which lists all firms targeted by stock spams since 1999. Our sample contains 110 manipulation cases that happened in both the Over-The-Counter Bulletin Board (OTCBB) and the Pink Sheets markets from February 2006 to October 2008. These two markets do not have a physical place as the NYSE or the AMEX; they are only represented by a computer network that displays the share prices in real time. Firms quoted on these markets are very speculative which is why they are targeted by manipulators. They are called penny stock firms. Penny stock means that the stock price is extremely low. Generally, the share price is below 5 dollars. For every manipulated stock, we use Datastream to obtain daily prices and trading volumes. 


\section{Data Analysis Method}

To study the impact of stock price manipulation on liquidity, we use the event studies methodology. For every stock, we have 161 daily volumes and closing prices ${ }^{2}$. The event day, denoted by $t=0$, is the day when the manipulator sends spams. The estimation window extends from date $t=-146$ to $t=-6$ and the event window extends from 5 days before the event day $(t=-5)$ to 14 days after the event day $(t=+14)$ (Figure 2). Starting with day $t=-5$ for the event window allows observation of the behaviour of spammers and to check whether or not liquidity is affected before the event day.

Figure 2: Estimation Window And Event Window

\begin{tabular}{|ccccc|}
\hline & Estimation window & $\mathrm{t}=0$ & $\mathrm{t}$ \\
$\mathrm{t}=-146$ & $\mathrm{t}=-6$ & $\mathrm{t}=-5$ & Event window \\
\hline
\end{tabular}

Abnormal liquidity is computed for each stock $i$ on each day $t$ in the event window as:

$$
A L_{i, t}=O L_{i, t}-T L_{i, t}
$$

where

$O L_{i t}$ the real or observed liquidity of stock $i$ on day $t$

$T L_{i t:}$ the theoretical liquidity of stock $i$ on day $t$

Consistent with the methodology in previous studies, we use the stock's average liquidity over the estimation window to estimate the theoretical liquidity. Mai and Tchemeni (1996), in a simulation study, underline that the use of the historical average of a variable gives more specified and appropriate results than the use of the market model or the standardized model.

Our hypotheses in this analysis are:

$\left\{\begin{array}{l}\mathbf{H}_{\mathbf{O}}: \text { Absence of abnormal liquidity } \\ \mathbf{H}_{\mathbf{1}}: \text { Presence of abnormal liquidity }\end{array}\right.$

\section{RESULTS}

\section{Cross-sectional Student Test}

To test and measure the significance of the existence of abnormality, a cross-sectional student test is applied by using the following statistic:

$\theta_{t}=\frac{M A L_{t}}{\sigma_{t}(M A L)}$

where

\footnotetext{
${ }^{2}$ It is the maximum number that we can obtain due to the unavailability of historical data for some securities. 
- $M A L_{t}$ : mean abnormal liquidity for all stocks at every date of the event window. It is given by:

$M A L_{t}=\frac{1}{110} \sum_{i=1}^{110} A L_{i, t}$

- $\sigma_{t}(M A L)$ : standard deviation of mean abnormal liquidity. It is computed at every date of the event window as follows:

$\sigma_{t}(M A L)=\frac{\sqrt{\frac{1}{110-1} \sum_{i=1}^{110}\left(A L_{i, t}-M A L_{t}\right)^{2}}}{\sqrt{110}}$

As shown in Table 1 and Figure 3, the manipulation of stock prices has generated an increase in liquidity. In the pre-announcement period (from $t=-5$ to $t=-1$ ), MALs do not show a stable trend; they climb slightly from $t$ $=-5$ to $t=-4$ and drop during the following days until one day prior the date of announcement where they increase highly (+11.7). However, these variations are not significant, which displays the expertise of manipulators. Indeed, they purchase a large quantity of stocks without significant effect on prices. At date $t=0$, manipulators begin the sending of spam and consequently MALs increase progressively until $t=4$ where we notice the biggest value of MAL (+9.30). This implies that transactions between buyers and sellers increase. Buyers - the investors - believe in the information contained in the message and buy stocks massively and sellers - the manipulators - benefit from this movement and sell all their stocks. After this market's resuscitation, MALs fall until $t=7$. As this decrease is not significant, we thought that the impact was finished. However, from $t=8$ to $t=13$, we again observed positive and significant MALs. This finding can be explained by the fact that manipulators have restarted a new advertising campaign in order to earn more money.

Table 1: Mean Abnormal Liquidities $\left(.10^{6}\right)$ And Statistics Of Student

\begin{tabular}{|c|c|c|}
\hline Date & $\boldsymbol{M A L}_{\boldsymbol{t}}(\mathbf{\%})$ & $\boldsymbol{\theta}_{\mathbf{t}}$ \\
\hline-5 & +5.51 & 1.92 \\
\hline-4 & +6.12 & 1.56 \\
\hline-3 & +3.75 & 0.80 \\
\hline-2 & +1.09 & 1.85 \\
\hline-1 & +11.7 & 0.76 \\
\hline 0 & +0.98 & $3.18^{* *}$ \\
\hline 1 & +4.73 & $2.76^{* *}$ \\
\hline 2 & +4.89 & $2.49^{* *}$ \\
\hline 3 & +4.97 & $2.19^{*}$ \\
\hline 4 & +9.30 & 1.28 \\
\hline 5 & +3.60 & 1.84 \\
\hline 6 & +1.86 & 0.97 \\
\hline 7 & +0.75 & $2.76^{* *}$ \\
\hline 8 & +1.56 & $2.32^{*}$ \\
\hline 10 & +3.43 & $2.93^{* *}$ \\
\hline 11 & +2.31 & $2.01^{*}$ \\
\hline 12 & +7.89 & $3.31^{* * *}$ \\
\hline 13 & +2.83 & $3.15^{* *}$ \\
\hline 14 & +3.08 & 0.96 \\
\hline
\end{tabular}

* significant at $5 \%$

** significant at $1 \%$

*** significant at $0.1 \%$

(C) 2013 The Clute Institute http://www.cluteinstitute.com/ 
This form of manipulation considerably affects the behaviour of investors who react favourably to the false information sent by manipulators. Indeed, investors, having a modest budget, cannot invest in well-known stock exchange like NYSE or NASDAQ. When they receive the message of spam, they believe its content in the hope of becoming rich because the manipulator promises them a huge fortune if they follow his advice. So they respond positively to the request of the manipulator by buying a large volume of stocks. By their movement of purchase, investors resuscitate the market activity, leading to an increase in liquidity and manipulators achieve their aim, which is making profits from the purchases of investors. Therefore, we reject the null Hypothesis $\mathrm{H}_{0}$.

Our results are consistent with those of Bouraoui $(2007,2011)$ who finds that this form of manipulation has generated a positive and significant impact on trading volumes and volatility, respectively. Similarly, Muscarella and Piwower (2001) show a positive impact on liquidity due to stock transfer between call trading and continuous trading.

Figure 3: Evolution Of MALs During The Event Window

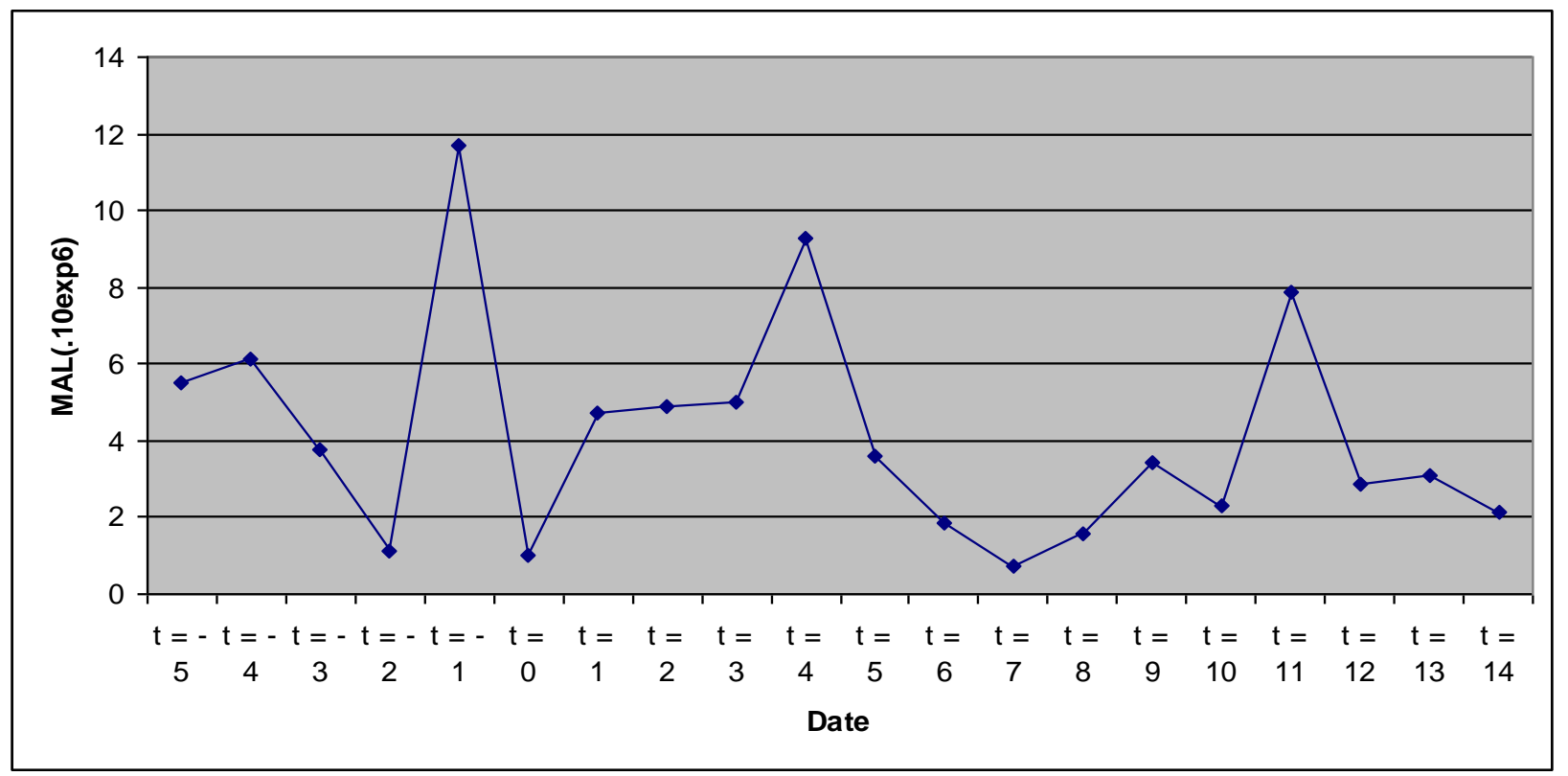

Although some of the MALs are statistically significant in the student test, we cannot limit our analysis only to these findings because the student test is a parametric test in which some hypotheses are not satisfied, such as the normality of data, equality between variances, etc. So, to cure these limits and to improve our results, we apply a non-parametric test.

\section{Generalized Sign Test}

The generalized sign test is a non-parametric test for which it is not necessary to specify the conditions that the sample has to fulfill. Corrado and Zivney (1992) underline that this test is more powerful than the student test as data are not distributed according to a normal law. Cowan (1992) also reports that the generalized sign test is well specified when the variance of the stock is not constant during the event window.

Under the null hypothesis, the generalized sign test compares the number of positive abnormal liquidities during the event window to the proportion expected in the estimation window. In this way, it takes account of an eventual asymmetric liquidity distribution. The generalized sign test statistic is: 


$$
Z_{g s}=\frac{N^{+}-p \cdot N}{\sqrt{p \cdot N(1-p)}}
$$

where

$N^{+}$: number of positive abnormal liquidities during the event window

$N$ : size of the sample

$p$ : fraction of positive abnormal liquidities in the 141-day estimation period

$$
p=\frac{\sum_{i=1}^{N} \frac{\sum_{t=1}^{141} S_{i t}}{141}}{N}
$$

where

$S_{i t}= \begin{cases}1 & \text { if } A L_{i t}>0 \\ 0 & \text { otherwise }\end{cases}$

The $\mathrm{N}^{+}$and t-statistics are summarized in Table 2 .

Table 2: Generalized Sign Test

\begin{tabular}{|c|c|c|}
\hline Date & $N^{+}$ & $Z_{g s}$ \\
\hline-5 & 34 & 1,64 \\
\hline-4 & 33 & $2,31 *$ \\
\hline-3 & 37 & $3,64 * * *$ \\
\hline-2 & 43 & $3,20 * *$ \\
\hline-1 & 41 & $5,65 * * *$ \\
\hline 0 & 52 & $6,09 * * *$ \\
\hline 1 & 54 & $5,87 * * *$ \\
\hline 2 & 53 & $5,20^{* * *}$ \\
\hline 3 & 50 & $5,20^{* * *}$ \\
\hline 4 & 50 & $4,31 * * *$ \\
\hline 5 & 46 & $2,97 * *$ \\
\hline 6 & 40 & $3,42 * * *$ \\
\hline 7 & 42 & $3,20 * *$ \\
\hline 8 & 41 & $3,20 * *$ \\
\hline 9 & 41 & $4,09 * * *$ \\
\hline 10 & 45 & $2,97 * *$ \\
\hline 11 & 40 & $4,31 * * *$ \\
\hline 12 & 46 & $3,42^{* * *}$ \\
\hline 13 & 42 & 1,19 \\
\hline
\end{tabular}

* significant at $5 \%$

** significant at $1 \%$

*** significant at $0.1 \%$

Findings show that most of the number of positif abnormal liquidities is significant during the event window. The evolution of $\mathrm{N}+$ in the pre-announcement period (from $\mathrm{t}=-5$ to $\mathrm{t}=-1$ ) clearly point out the purchases made by manipulators to prepare their advertising campaign $-\mathrm{N}+\operatorname{climbs}$ from 34 at date $\mathrm{t}=-5$ to 41 at date $\mathrm{t}=-1$. 
The largest number of positive abnormal liquidities is observed at date $t=1$. Indeed, 54 corporations among 110 have seen their stocks more liquid on this day. To follow the advice of the manipulator, investors buy a massive amount of stocks and manipulators find it easy to sell all the stocks purchased earlier, which contributes to improving liquidity. The following day $(\mathrm{t}=2)$, the number $\mathrm{N}+$ declines progressively until the end of the event window.

As most of the $\mathrm{N}+$ is statistically significant, we cannot exclude that sending stock spams has negatively generated abnormal liquidities. However, this number is very weak ahead of the positive abnormal liquidities. In other words, through their messages, manipulators have exhorted some naïve investors to invest in penny stocks and, at the same time, have discouraged others who are vigilant; but the number of those who stopped theirs transactions due to the message of stock spams is negligible in comparison to the number of those who believed in the manipulator's message.

In summary, we find strong evidence - through the student test and, in particular, the generalized sign test that manipulating penny stocks generates an increase in liquidity.

\section{CONCLUSION}

Previous evidence from penny stock markets (Bouraoui $(2007,2011)$ ) has shown that stock spams caused a positive and significant impact on trading volumes and volatility, respectively. The aim of this study is to examine the impact of this information-based manipulation on liquidity. The implementation of an event study methodology exhibits significant positive abnormal liquidities for stocks targeted by manipulators. These results are consistent with the findings of Bohme and Holz (2006), Frieder and Zittrain (2007) and Hanke and Hauser (2008) who found significant impact of this manipulation form on volume, return, and volatility.

Although investors have learned, during previous campaigns of manipulation of stock prices, that the information sent by the manipulator is false and this kind of stock is very speculative and risky, they continue to believe in such information, so manipulators succeed in earning money by selling stocks at higher prices. This fact may be due to either these investors do not have a sufficient budget that enables them to invest in well-known stock markets, like Amex or Nasdaq, so they invest in penny stocks in the hope of making money, or manipulators are very clever and experienced - they target a new set of victims every time by collecting new e-mail addresses.

As the results obtained in this paper are aggregated for all stocks in the sample, establishing a detailed study that focuses on the impact of every stock or trying to determine why investors invest in such stocks will be a challenge for researchers in the future to provide more explanations for this kind of manipulation.

\section{AUTHOR INFORMATION}

Taoufik Bouraoui is professor of Finance at ESC-Rennes School of Business, France. His research focuses on financial markets, business, international finance and financial risk management. He published several articles in Applied Financial Economic, Brussels Economic Review, International Review of Business Research Papers and International Journal of Economics and Finance. E-mail: taoufik.bouraoui@esc-rennes.fr (Corresponding author)

Mohamed Mehanaoui is professor of Finance at SUP de CO AMIENS, France and he is also researcher at EconomiX Laboratory, CNRS UMR 7235. His Fields of interest are International finance (exchange rates; financial integration), econometrics and modelling and high frequency data modelling. E-mail: mohamed.mehanaoui@supco-amiens.fr

Bouchaib Bahli is Professor of Management Information Systems at ESC-Rennes School of Business, France. His research focuses on information governance, outsourcing, strategic alignment of information technology and decision making management. His work has been published in such journals as Information and Management, Journal of Information Technology, OMEGA The International Journal of Management Science, Business Process Management Journal and others. E-mail: bouchaib.bahli@esc-rennes.fr 


\section{REFERENCES}

1. Adaoglu, C. (2005). Market reaction to unsweetened and sweetened rights offerings in an emerging European stock market. Journal of Multinational Financial Management, 16, 249-268.

2. Aggarwal, R.K \& Wu, G. (2006). Stock market manipulations. Journal of Business, 79, 1915-1953.

3. Aktas, R. \& Doganay, M. (2006). Stock-price manipulation in the Istanbul stock exchange. Eurasian Review of Economics and Finance. 2, 21-28.

4. Allen, F. \& Gale, D. (1992). Stock-price manipulation. The Review of Financial Studies. 5, 503-529.

5. Allen, F. \& Gorton, G. (1992). Stock price manipulation, market microstructure and asymmetric information. European Economic Review. 36, 624-630.

6. Amihud, Y., Mendelson, H. \& Lauterbach, B. (1997). Market microstructure and securities values: Evidence from the Tel Aviv Stock Exchange. Journal of Financial Economics. 45, 365-390.

7. Bagnoli, M. \& Lipman, B.L. (1996). Stock price manipulation through takeover bids. The RAND Journal of Economics. 27, 124-147.

8. Berkman, H. \& Eleswarapu, V.R. (1998). Short-term traders and liquidity: a test using Bombay Stock Exchange Data. Journal of Financial Economics. 47, 339-355.

9. Bohme, R. and Holz, T. (2006). The Effect of Stock Spam on Financial Markets. SSRN Working paper $\mathrm{N}^{\mathrm{o}}$. 897431 http://www.dihe.de/docs/docs/SSRN-id897431.pdf

10. Bouraoui, T. (2007). L'impact des spams boursiers sur les volumes, Brussels Economic Review. 50, 411 425.

11. Bouraoui, T. (2009). Stock Spams: An Empirical Study on Penny Stock Market. International Review of Business Research Papers 5, 292-305.

12. Bouraoui, T. (2011). The impact of stock spams on volatility. Applied Financial Economic. 22, 969-977.

13. Chakraborty, A. \& Yilmaz, B. (2004). Informed manipulation. Journal of Economic Theory. 114, 132-152.

14. Corrado, C.J. \& Zivney, T.L. (1992). The specification and power of the sign test in event study hypothesis tests using daily stock returns. The Journal of Financial and Quantitative Analysis. 27, 465-478.

15. Cowan, A.R. (1992). Nonparametric event study tests. Review of Quantitative Finance and Accounting. 2, 343-358.

16. Felixon, K. \& Pelli, A. (1999). Day end returns - Stock price manipulation. Journal of Multinational Financial Management. 9, 95-127.

17. Frieder, L.L. \& Zittrain, J.L. (2007). Spam Works: Evidence from Stock Touts and Corresponding Market Activity. Harvard Public Law Working paper N. 135

http://heinonline.org/HOL/LandingPage?collection=journals\&handle=hein.journals/hascom30\&div=22\&id =\&page $=$

18. Glosten, L. \& Milgrom, P. (1985). Bid, ask and transaction prices in a specialist market with heterogeneously informed traders. Journal of Financial Economics. 13, 71-100.

19. Hanke, M. \& Hauser, F. (2008). On the Effects of Stock Spam e-mails. Journal of Financial Markets. 11, 57-83.

20. Huang, Y.C. Chen, R.C.Y. \& Cheng, Y.J. (2005). Stock manipulation and its impact on market quality, working paper, National Kaohsiung First University of Science and Technology, Kaohsiung 811, Taiwan, ROC http://www.finance.nsysu.edu.tw/SFM/14thSFM/FullPapers/060.pdf

21. Kumar, P. \& Seppi, D.J. (1992). Futures manipulation with cash settlement. Journal of Finance. 47, 14851502.

22. Mai, H.M. \& Tchemeni, E. (1996), Etude d'événement par les volumes: méthodologies et comparaison, cahier de recherche du CEREG, No.10, University of Dauphine (France). http://www.cereg.dauphine.fr/cahiers_rech/cereg9610.pdf

23. Muscarella, C.J. \& Piwowar, M.S. (2001). Market microstructure and securities values: Evidence from the Paris Bourse. Journal of Financial Markets. 4, 209-229.

24. Ögüt, H. Doganay, M.M. \& Aktas, R. (2009). Detecting stock-price manipulation in an emerging market: The case of Turkey, Expert Systems with Applications. 36, 11944-11949.

25. Pirrong, C. (2004). Detecing manipulations in futures markets: The Ferruzzi Soybean episode. American law and economics review. 6, 28-71.

26. Van Bommel, J. (2003). Rumors. The Journal of Finance. 58, 1499-1519.

27. Vila, J.L. (1989). Simple games of market manipulation. Economic Letters 29, 21-26.

(C) 2013 The Clute Institute http://www.cluteinstitute.com/ 
28. Vitale, P. (2000). Speculative noise trading and manipulation in the foreign exchange market. Journal of International Money and Finance.19, 689-712. 